\title{
Potencial ornamental de espécies do Bioma Caatinga
}

\author{
Markilla Zunete Beckmann Cavalcante*, Daniel Fagner da Silva Dultra, \\ Handerson Leandro da Costa Silva, Jarina Coelho Cotting, \\ Sheila Daniella Pereira da Silva, José Alves de Siqueira Filho
}

Universidade Federal do Vale do São Francisco, Petrolina,PE, Brazil

*Autor correspondente, e-mail: markilla.beckmann@univasf.edu.br

\section{Resumo}

A redução ou substituição de plantas ornamentais exóticas por espécies nativas com potencial ornamental é uma tendência atual do paisagismo. A inserção na cadeia produtiva de flores e plantas ornamentais e disponibilidade para a comercialização representa um diferencial em um mercado altamente competitivo, atento à novidades e com tendência a adotar produtos de impacto ambiental reduzido além promover a conservação ex situ. Neste sentido, objetivouse prospectar espécies da flora nativa do Bioma Caatinga ocorrentes no Vale do Submédio São Francisco que apresentem elementos estéticos apropriados para uso no paisagismo. Foram realizadas incursões em campo para identificação das espécies e descritos o hábito de crescimento, a forma, a simetria, a estrutura, textura e cor das estruturas de maior valor ornamental, o aroma, a presença ou não de espinhos e indicadas às possibilidades de uso das espécies. Foram indicadas um total de 43 espécies, distribuídas entre hábito herbáceo (21), hábito arbustivo (1 1), arbóreas (9), uma trepadeira e um cipó. Dentre as espécies indicadas, 30,2\% pertencem à família Fabaceae. A flora da Caatinga apresenta espécies com enorme potencial ornamental para diversos usos e efeitos paisagísticos. Há necessidade de estimular o uso de espécies nativas do Bioma Caatinga em projetos de paisagismo, cujo potencial ainda é pouco valorizado.

Palavras-chave: flora nativa, floricultura, paisagismo, condições semiáridas

\section{Ornamental potential of Caatinga Biome species}

\begin{abstract}
The reduction or replacement of exotic ornamental plants by native species with ornamental potential is a current trend of landscaping. The insertion in the productive chain of flowers and ornamental plants and availability for commercialization represents a differential in a highly competitive market, attentive to novelties and tending to adopt products of reduced environmental impact besides promoting ex situ conservation. In this sense, the objective was to prospect species of the native flora of the Caatinga Biome that occur in the Valley of the Submédio São Francisco that present aesthetic elements appropriate for use in the landscaping. Incursions were made in the field to identify the species and were described the habit of growth, shape, symmetry, structure, texture and color of structures of higher ornamental value, fragrance, the presence of spines or not with indication of the possibilities of use. A total of 43 species were reported, distributed among herbaceous habit (21), bush habit (11), arboreal trees (9), both one climbing and hardy liana. Among the species indicated, $30.2 \%$ belong to the Fabaceae family. The flora of the Caatinga presents species with high ornamental potential for diverse uses and landscape effects. There is a need to stimulate the use of native species of the Caatinga Biome in landscaping projects, whose potential is still little valued.
\end{abstract}

Keywords: native flora, floriculture, landscape, semiarid conditions 


\section{Introdução}

O Brasil abriga a flora mais megadiversa do mundo, representada pelos biomas Amazônia, Caatinga, Cerrado, Mata Atlântica, Pampa e Pantanal (Forzza et al., 2012). A composição vegetal da Caatinga é representada por cerca de 5000 espécies, com expressivo número de espécies endêmicas (em torno de 380) (Siqueira Filho, 2012). Alvarez \& Kiill (2014) relatam que pouco se sabe sobre $\bigcirc$ aproveitamento econômico da biodiversidade existente nessa vegetação. Dentre as potencialidades a serem exploradas, tem-se o mercado das plantas ornamentais, seja para paisagismo como arte floral.

Fischer et al. (2007)mencionam que, por razões culturais, desde a época colonial o paisagismo no Brasil prioriza $\circ$ uso de plantas exóticas sobre as nativas. De fato, o potencial ornamental da flora brasileira vem sendo menosprezado especialmente pela tradição no uso de plantas exóticas, cujos processos de cultivo e manutenção estão há muito dominados (Stumpf et al., 2008). Por outro lado, Heiden et al. (2007b) reportam que o potencial ornamental de muitas espécies nativas brasileiras tem sido reconhecido por outros países. Os autores mencionam que diversas espécies foram levadas daqui e incorporadas a programas de melhoramento genético desenvolvidos por empresas estrangeiras. Posteriormente importadas pelo Brasil, os híbridos desenvolvidos foram inseridos como novidades no mercado nacional, obtendo boa aceitação. O fato evidencia, assim, o potencial de uso ornamental das plantas nativas e a dependência do consumidor brasileiro pela opinião de outros mercados.

A redução no uso de plantas ornamentais exóticas ou sua total substituição por espécies nativas é uma tendência atual do paisagismo. De acordo com Heiden et al. (2006), - uso de espécies nativas em áreas verdes planejadas, ao mesmo tempo em que colabora para a preservação da flora local, é capaz de reforçar identidades regionais. Além disso, a inserção de plantas nativas na cadeia produtiva da floricultura representa um diferencial em um mercado altamente competitivo, atento à novidades e com tendência a adotar produtos de impacto ambiental reduzido. 0 reconhecimento de características ornamentais nestas espécies é o passo inicial para a produção e comercialização (Heiden et al., 2007a), bem como para o estabelecimento protocolos de propagação e de programas nacionais de melhoramento genético de plantas ornamentais (Cardoso, 2013; Beckmann-Cavalcante et al., 2014). De acordo com Stumpf et al. (2009), a inserção dessas plantas em cultivos comerciais e sua posterior utilização são também formas efetivas de colaborar com a conservação ex situ.

No Brasil, vários estudos com espécies nativas e endêmicas para uso no paisagismo têm mostrado resultados positivos que evidenciam perspectivas de novidades para a floricultura nacional. Leal \& Biondi (2006), por exemplo, identificaram o potencial ornamental de 25 espécies nativas no estado do Paraná, enquanto que no Rio Grande do Sul, desde 2006, estudos com plantas nativas têm se destacado no meio científico, a exemplo de Heiden et al. (2007a, 2007b) e Stumpf et al. (2008, 2009). Para - semiárido nordestino, os relatos científicos ainda são escassos, mas Alvarez \& Kiill (2014) destacam as cactáceas e bromélias como produto promissor da floricultura.

Com base no exposto, o presente trabalho foi desenvolvido com o objetivo de prospectar espécies da flora nativa do Bioma Caatinga ocorrentes no Vale do Submédio São Francisco que apresentem elementos estéticos apropriados para uso no paisagismo.

\section{Material e Métodos}

Inicialmente foi realizada consulta à base de dados do Herbário do Vale do São Francisco da Universidade Federal do Vale do São Francisco (HVASF/UNIVASF) para a identificação de espécies nativas e endêmicas do Bioma Caatinga que apresentassem características indicativas de uso ornamental (hábito, cor e textura das estruturas de maior valor ornamental (folhas, ramos, caule, flores, frutos). Posteriormente, com auxílio do Software Carolus (programa que permite o controle e organização do acervo do HVASF), foi gerado 
um banco dos pontos de georreferenciamento das espécies previamente selecionadas para auxiliar na localização dentro da área do Campus de Ciências Agrárias/UNIVASF, Petrolina, Pernambuco. De acordo com o sistema brasileiro de classificação da vegetação (IBGE, 2012), na região predomina a fitofisionomia Savana Estépica (Savana seca e/ou úmida da Caatinga do Sertão Árido).

Com base no banco de informações, no período de janeiro de 2014 à janeiro de 2015 foram realizadas incursões quinzenais em campo para localização e identificação das espécies previamente selecionadas. Todas as plantas encontradas com base no georreferenciamento existente foram confrontadas com as exsicatas depositadas no HVASF para a confirmação de sua identificação botânica, fundamental para a continuidade do trabalho. Foi gerado um mapa com os pontos de localização das plantas a partir do Software Arc GIS 10.1 (Figura 10.1)

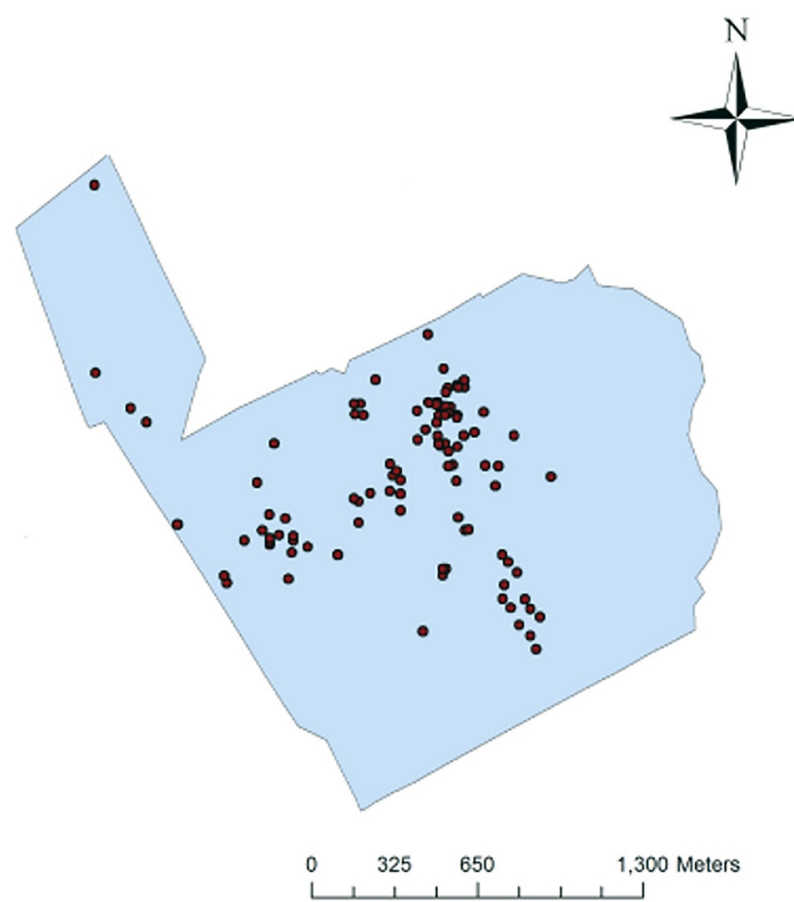

Figura 1. Mapa com as delimitações do Campus de Ciências Agrárias da UNIVASF e pontos de localização das espécies nativas e endêmicas do Bioma Caatinga selecionadas por suas características ornamentais. Petrolina-PE, 2015.

Para a descrição das características ornamentais das espécies selecionadas e eliminar ao máximo as preferências pessoais, foi aplicada a metodologia proposta por Stumpf et al. (2009), com modificações, levando-se em consideração também a caraterística de presença e/ou ausência de espinhos, e para hábito, considerou-se também o grupo das trepadeiras e cipós.

Ainda de acordo com a metodologia, as plantas foram categorizadas em: plantas para jardins (indicadas para a formação de forrações, maciços, bordaduras, cercas-vivas ou para uso isolado); plantas para vasos (indicadas para $\circ$ cultivo em recipientes de diferentes volumes); ou plantas multifuncionais (indicadas tanto para o emprego em jardins como para o cultivo em vasos).

\section{Resultados e discussão}

Inicialmente foram identificadas 143 espécies entre nativas e endêmicas após consulta ao HVASF com características indicativas de uso ornamental. Durante as incursões, foram identificadas 43 espécies em campo (Tabela 1), no entanto, para algumas, foram encontradas mais de um indivíduo por espécie, o que justifica o maior número de pontos apresentados no mapa (Figura 1). 
Tabela 1. Lista de espécies do Bioma Caatinga encontradas no Campus Ciências Agrárias/UNIVASF e selecionadas pelo potencial ornamental. Petrolina-PE, 2014-2015

\begin{tabular}{|c|c|c|c|}
\hline Espécie & Nome Vulgar & Família & Endemismo* \\
\hline Ruellia asperula (Mart. ex Ness) Lindau & Melosa & Acanthaceae & Não \\
\hline Gomphrena desertorum Mart. & Suspiro-branco & Amaranthaceae & Não \\
\hline Habranthus sylvaticus Herb. & Lírio-da-caatinga & Amaryllidaceae & Não \\
\hline Schinopsis brasiliensis Engl. & Baraúna, braúna & Anacardiaceae & Sim \\
\hline Allamanda puberula A.DC & Quatro-patacas & Apocynaceae & Não \\
\hline Varronia leucocephala (Moric.) J.S.Mill. & Moleque-duro & Boraginaceae & Sim \\
\hline Bromelia laciniosa Mart. ex Schult. \& Schult.f. & Macambira-de-cachorro & Bromeliaceae & Sim \\
\hline Neoglaziovia variegata (A) Mez & Caroá & Bromeliaceae & Sim \\
\hline Commiphora leptophloeos (Mart.) J.B.Gillett & Imburana-de-cambão & Burseraceae & Não \\
\hline Cereus jamacaru DC. subsp. jamacaru & Mandacarú & Cactaceae & Não \\
\hline Melocactus zehntneri (Britton \& Rose) Luetzelb. & Coroa-de-frade & Cactaceae & Não \\
\hline Tacinga inamoena (K.Schum.) N.P.Taylor \& Stuppy & Quipá & Cactaceae & Não \\
\hline Fraunhofera multiflora Mart. & Pau-branco & Celastraceae & Sim \\
\hline Evolvulus cordatus Moric. & Azul-rasteira & Convolvulaceae & Não \\
\hline Ipomoea incarnata (Vahl) Choisy & Jitirana & Convolvulaceae & Não \\
\hline Cnidoscolus quercifolius Pohl & Faveleira & Euphorbiaceae & $\operatorname{sim}$ \\
\hline Jatropha mollissima (Pohl) Baill. & Pinhão-bravo & Euphorbiaceae & Não \\
\hline Amburana cearensis (Allemão) A.C.Sm & Umburana-de-cheiro & Fabaceae & Não \\
\hline Anadenanthera colubrina (Vell.) Brenan & Angico-de-caroço & Fabaceae & Não \\
\hline Calliandra leptopoda Benth. & Caliandra, esponjinha & Fabaceae & Sim \\
\hline Calliandra macrocalyx Harms & Caliandra & Fabaceae & $\operatorname{sim}$ \\
\hline Chamaecrista repens (Vogel) H.S.Irwin \& Barneby & - & Fabaceae & Não \\
\hline Dioclea grandiflora Mart. ex Benth & Mucunã & Fabaceae & $\operatorname{sim}$ \\
\hline Libidibia ferrea (Mart. ex Tul.) L.P.Queiroz var. ferrea & Pau-ferro; Jucá & Fabaceae & $\operatorname{sim}$ \\
\hline Luetzelburgia bahiensis Yakovlev & - & Fabaceae & Não \\
\hline Mimosa ophthalmocentra Mart. ex Benth & Jurema-branca & Fabaceae & $\operatorname{sim}$ \\
\hline Mimosa verrucosa Benth. & Jurema-rosa & Fabaceae & Sim \\
\hline Poincianella microphylla (Mart. ex G.Don) L.P.Queiroz & Catingueira-rasteira & Fabaceae & Sim \\
\hline Senna martiana (Benth.) H.S.Irwin \& Barneby & - & Fabaceae & $\operatorname{sim}$ \\
\hline Zornia brasiliensis Vogel & - & Fabaceae & Não \\
\hline Alophia linearis (Kunth) Klatt & Íris-do-campo & Iridaceae & Não \\
\hline Rhaphiodon echinus Schaver & Falsa-menta, beton & Lamiaceae & Não \\
\hline Pavonia cancellata (L.) Cav. & - & Malvaceae & Não \\
\hline Sida galheirensis Ulbr. & Malva & Malvaceae & Não \\
\hline Angelonia cornigera Hook.f. & Violeta-do-campo & Plantaginaceae & Não \\
\hline Diodella teres (Walter) Small & - & Rubiaceae & Não \\
\hline Mitracarpus baturitensis Sucre & - & Rubiaceae & Não \\
\hline Richardia scabra L. & - & Rubiaceae & Não \\
\hline Piriqueta duarteana (Cambess.) Urb. var. ulei Urb & Chanana & Turneraceae & Não \\
\hline Turnera subulata Sm. & Chanana & Turneraceae & Não \\
\hline Stachytarpheta microphylla Walp. & - & Verbenaceae & Sim \\
\hline $\begin{array}{l}\text { Vellozia cinerascens (Mart. ex Schult. \& Schult.f.) } \\
\text { Mart. ex Seub. }\end{array}$ & Velozia & Velloziaceae & Sim \\
\hline Selaginella convoluta (Arn.) Spring & Jericó & Selaginellaceae & Não \\
\hline
\end{tabular}
*Baseado nas informações de Siqueira Filho (2012) e Reflora (2016).

As espécies indicadas estão distribuídas em 22 famílias (Tabela 1), destacando-se a família Fabaceae, representada por 13 espécies $(30,2 \%)$. A observação confirma dados de levantamentos florísticos realizados nas áreas de Caatinga da Bacia Hidrográfica do Rio São Francisco e em afloramentos rochosos na Mesorregião do Agreste paraibano, respectivamente apresentados por Siqueira
Filho (2012) e Sales-Rodrigues et al. (2014), que indicaram ser a família Fabaceae a mais rica em espécies nos locais estudados. Dentre todas as espécies com características adequadas aos propósitos do trabalho, 17 espécies são consideradas endêmicas (Siqueira Filho, 2012; Reflora, 2016). Pelo fato de serem espécies que não são encontradas em outro ambiente, devem ser devidamente utilizadas para que não 
sejam alvos de extinção.

Dentre as espécies prospectadas, a endêmica Schinopsis brasiliensis Engl. (Figura 21), encontra-se na Lista Oficial das Espécies da Flora Brasileira Ameaçadas de Extinção (MMA, 2008). Espécies dos gêneros Amburana, Gomphrena, Ipomoea, Melocactus, Mimosa, Mitracarpus e Tacinga, porém distintas das espécies indicadas no presente estudo, também constam nesta lista. Muitas vezes as espécies são exploradas de forma aleatória para os mais diversos usos, levando-as quase a extinção pelo desconhecimento do manejo e uso potencial adequado. De acordo com Stumpf et al. (2009), a paulatina supressão da vegetação, constitui um grave problema ambiental, que afeta diretamente a biodiversidade do local. Os autores ressaltam ainda que no quadro atual de devastação do ambiente, a aplicação prática de plantas nativas com potencial ornamental, como uso no paisagismo, pode contribuir para a valorização e conservação da biodiversidade.

As características ornamentais que indicam a adequação das espécies para o uso no paisagismo, bem como suas possíveis aplicações de uso, estão sumarizadas na Tabela 2. Observa-se que a ocorrência das espécies no local de estudo apresentaram diferentes formas, simetrias, estruturas vegetais variando de flores e inflorescências à folhas e cladódios, aspectos da textura, diversidade em cores, presença e ausência ambos para aroma e espinhos. Esta variabilidade de características possibilita o uso no paisagismo em suas diversas formas, seja multifuncional (jardim e/ou vaso) ou para formação de jardins.

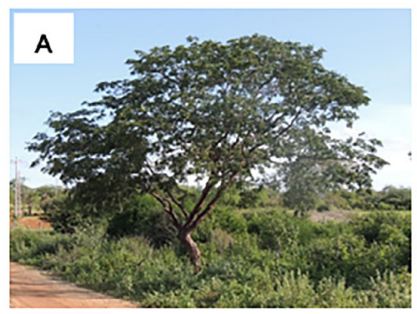

Amburana cearensis

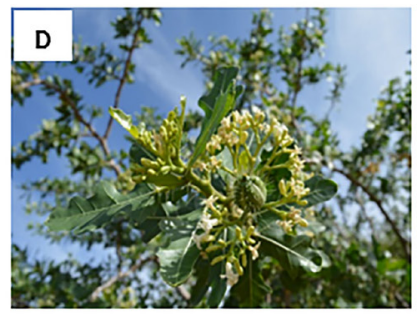

Cnidoscolus quercifolius

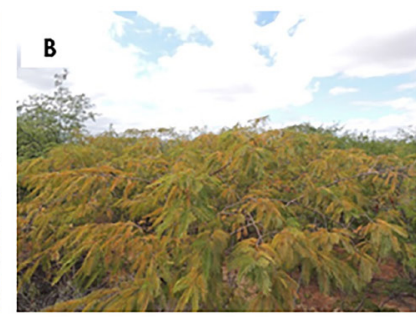

Anadenanthera colubrina

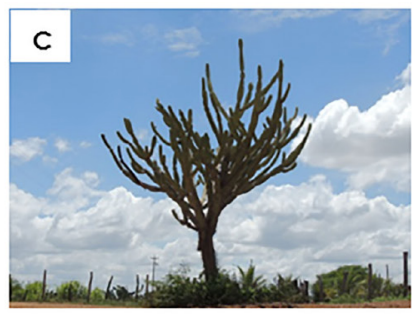

Cereus iamacaru

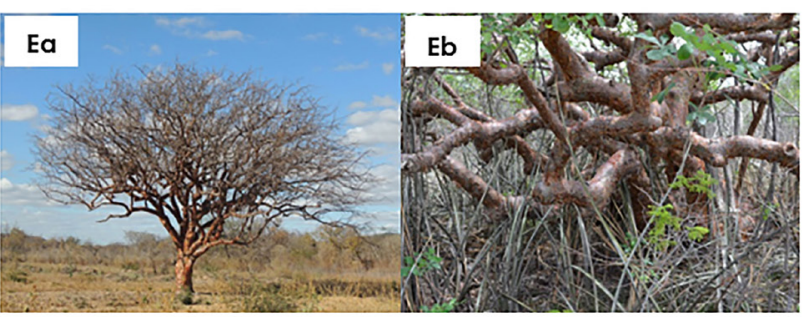

Commiphora leptophloeos

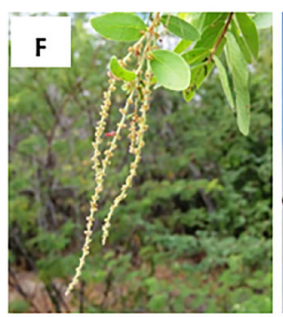

Fraunhofera multiflora

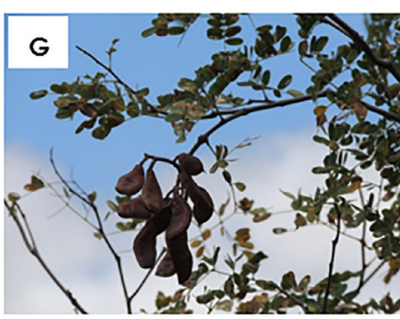

Libidibia ferrea
H

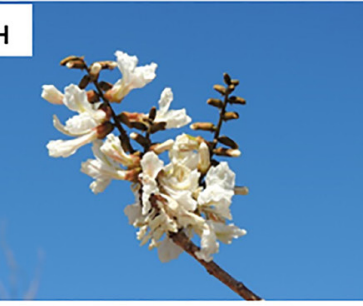

Luetzelburgia bahiensis

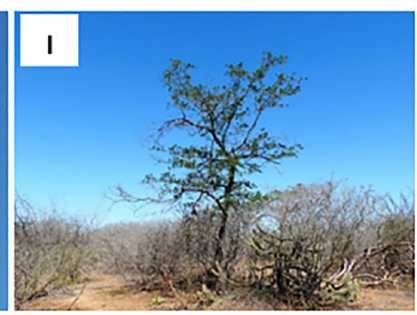

Schinopsis brasiliensis

Figura 2. Espécies arbóreas do Bioma Caatinga indicativas de uso no paisagismo. Características ornamentais do hábito (A, C E, J); Caule (F); Flores/Inflorescências (D, G, I); Folhas (B, D, G, H); Frutos (H). Petrolina-PE, 2014-2015. Fotos: Silva, H.L. da Costa \& Cotting, J.C.

Destaca-se que algumas espécies selecionadas apresentam espinhos em alguma estrutura da planta, a exemplo de Bromelia laciniosa (folhas), Melocactus zehntneri (praticamente a planta inteira), Neoglaziovia variegata (folhas), Tacinga inamoena (cladódios), Allamanda puberula (fruto), Mimosa ophthalmocentra (caule), Cereus jamacaru 
(cladódios) e Cnidoscolus quercifolius (planta inteira espinescente, Figura 2D) (Tabela 2). O Bioma Caatinga é conhecido pela vegetação xerófila, lenhosa caducifólia e espinhosa, com a queda de folhas na época da seca (marcada pela baixa disponibilidade hídrica), troncos esbranquiçados e folhas modificadas em espinhos. Estas caraterísticas são estratégias adaptativas à deficiência hídrica (Castro \& Cavalcante, 2010; Loiola et al., 2012). Na elaboração de um projeto de paisagismo, deve-se levar em consideração o público alvo, no entanto, a presença de espinhos nas plantas nem sempre deve ser considerada um aspecto negativo ao se indicar plantas para uso nos jardins. Plantas com espinhos podem ser indicadas, por exemplo, para compor jardins contemplativos, destinados ao prazer sensorial da visão, ou ainda, para atuar como barreiras físicas sem, no entanto constituir em barreiras visuais.

Conforme evidenciado, $48,8 \%$ das espécies indicadas possuem hábito herbáceo (Tabela 2). Foi notória a presença destas espécies ao longo das avaliações, ocorrendo tanto indivíduos jovens como adultos em plena fase de florescimento, o que resultou no maior número de pontos apresentados no mapa (Figura 1). Deduz-se que estas espécies apresentam facilidade na sua perpetuação. Malamut (2014) faz menção às plantas que tem facilidade de propagação e, ao longo do tempo, tornaremse invasoras, ocupando espaço e competindo com a flora existente, podendo causar prejuízo ao equilíbrio do ambiente original. Desta forma, reitera-se a necessidade de estudos para evitar uso indiscriminado de uma determinada espécie vegetal. É fundamental avançar na domesticação e no melhoramento genético das espécies e, conjuntamente, incrementar a respectiva conservação.

Segundo Leal \& Biondi (2006), plantas de porte herbáceo podem ser utilizadas como forração na composição de canteiros; como maciços combinados ou não com outras espécies; ou até mesmo como bordaduras, delimitando caminhos e canteiros.

Dentre as plantas do porte herbáceo (Figura 3 e 4), 42,9\% das espécies (Tabela 2) enquadram seu uso para forração, à exemplo de Chamaecrista repens (Figura 3D), Diodella teres (Figura 3E), Evolvulus cordatus (Figura 3F), Gomphrena desertorum (Figura 3G), Mitracarpus baturitensis (Figura 3J), Pavonia cancellata (Figura $4 \mathrm{~L}$ ), Rhaphiodon echinus (Figura 4N), Richardia scabra (Figura 4O), Selaginella convoluta (Figura $4 P$ ) e Zornia brasiliensis (Figura 4U). São plantas que podem ser utilizadas para a finalidade de forração, pela vistosidade de suas estruturas ornamentais e pelo rápido preenchimento de espaço dos locais onde foram caracterizadas. Segundo Malamut (2014), as forrações são usadas para dar unidade à paisagem, podendo substituir gramados, quebrar sua monotonia ou fazendo a transição entre estes e árvores e/ou arbustos. No entanto, são plantas que, apesar de formarem planos horizontais, podendo encobrir o solo e estruturalmente assumirem o papel de piso, não toleram ao pisoteio como os gramados, mas podem proteger o solo contra erosões originadas do vento e da chuva.

Dentre as espécies indicadas como forração (Tabela 2), Biondi (2013) também cita as espécies dos gêneros Evolvulus e Selaginella como plantas aptas para esta finalidade, especificamente para causar contraste na composição elaborada ou na paisagem existente. Também indica o uso para composição de maciços homogêneos e revestimento de taludes. Neste contexto, a espécie R. echinus (Figura $4 \mathrm{~N}$ ) é altamente indicativa para revestimento de taludes e barrancos, pelo fato de apresentar um crescimento acelerado recobrindo a superfície do solo.

A espécie S. convoluta (Tabela 2, Figura 4P), uma pteridófita, não apresenta flores, mas destaca-se pelo pouco crescimento, o verde de suas folhas e apresentam uma resistência à seca, no qual durante o período de estiagem, permanece enrolada e com aspecto de morta; porém com as primeiras chuvas, rapidamente recupera a turgidez das folhas. Estas características fazem dela uma planta interessante para uso no paisagismo como forração no qual sugere pouca manutenção e reduzido uso de água. Também foi documentada por Kiill et al. (2013) e Alvarez \& Kiill (2014) com potencialidade de uso como planta ornamental. 


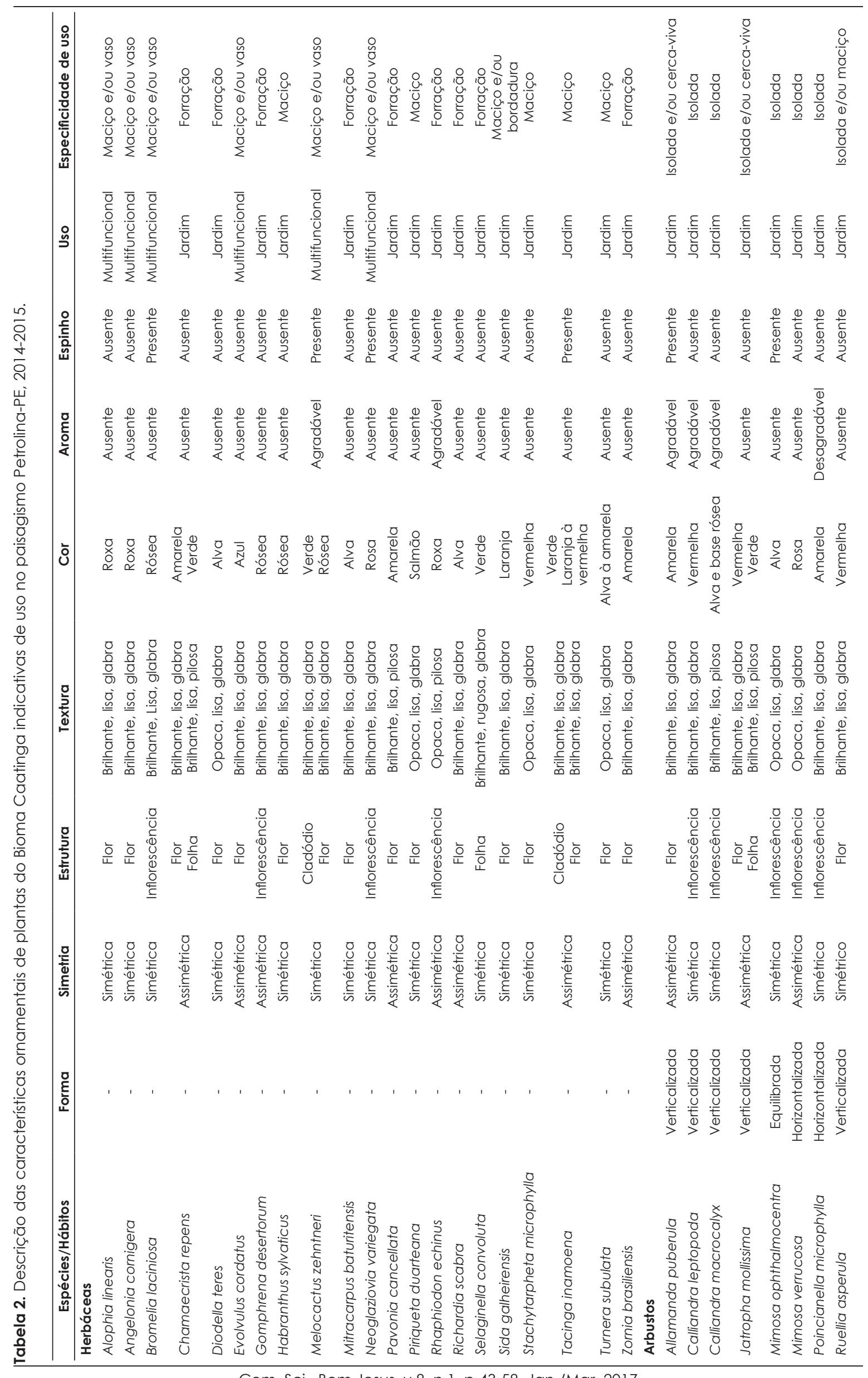

Com. Sci., Bom Jesus, v.8, n.1, p.43-58, Jan./Mar. 2017 


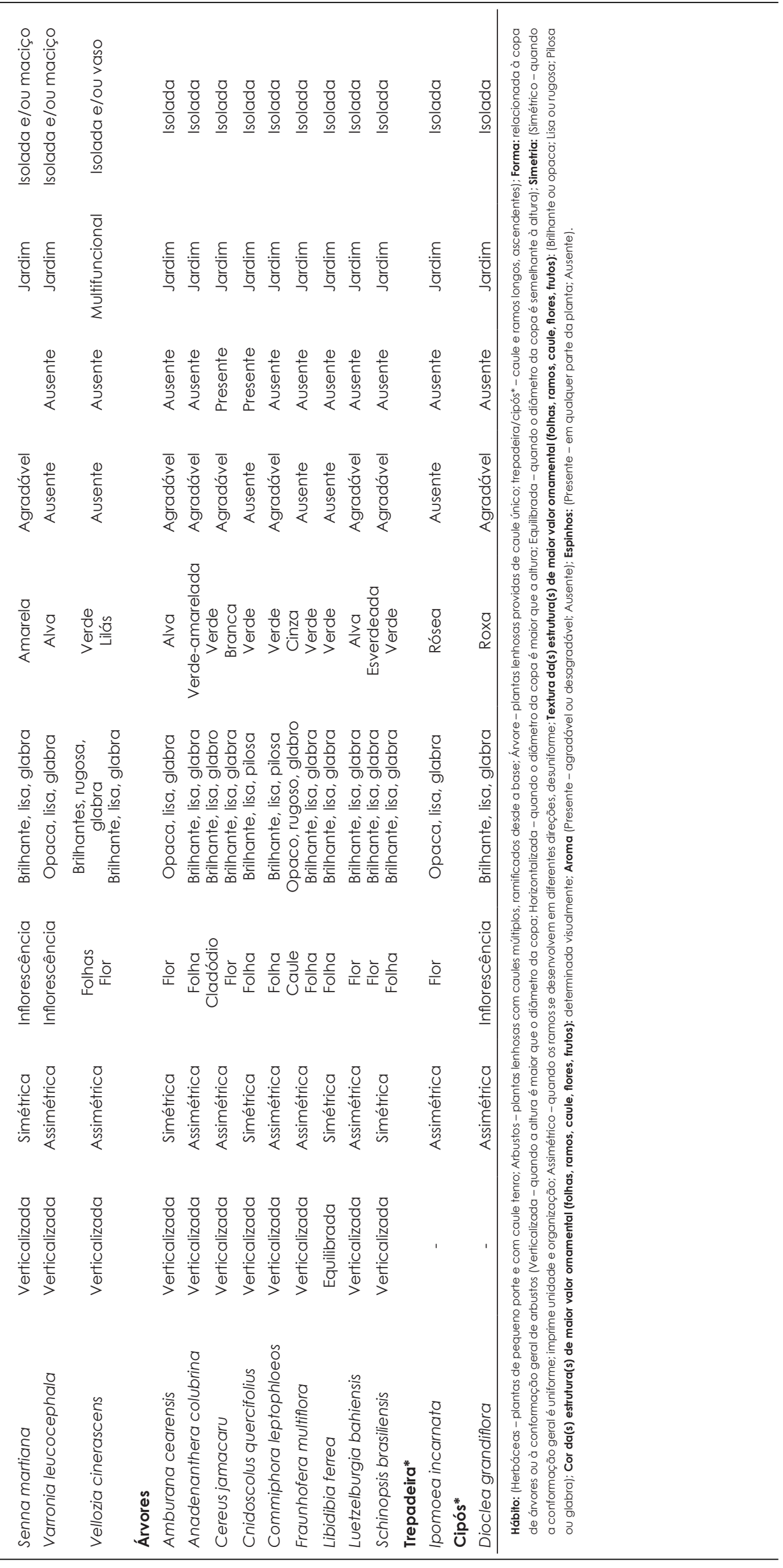

Com. Sci., Bom Jesus, v.8, n.1, p.43-58, Jan./Mar. 2017 

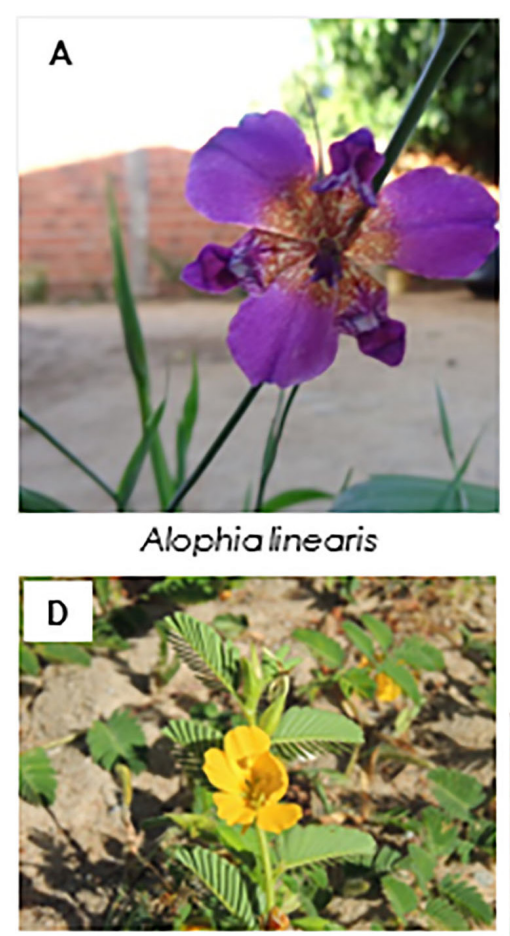

Chamaecristarepens

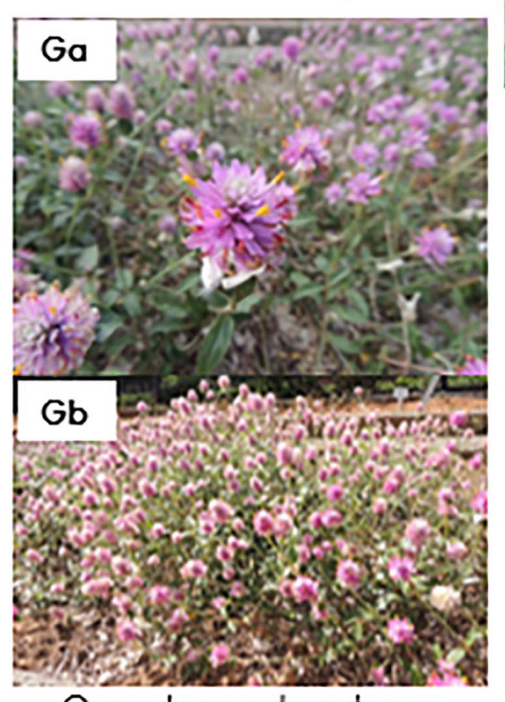

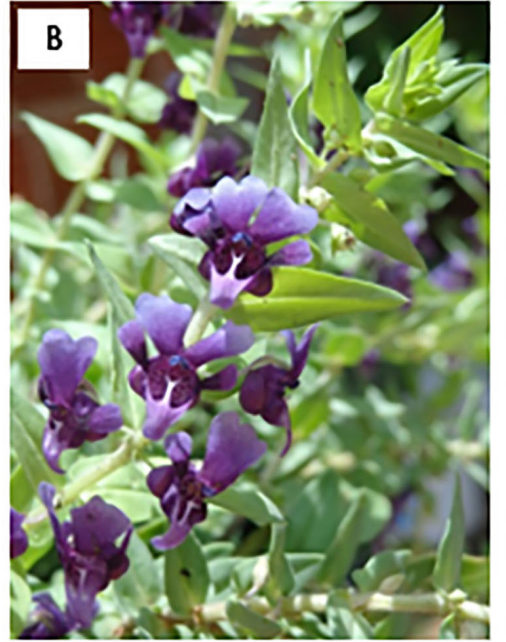

Angelonia comigera

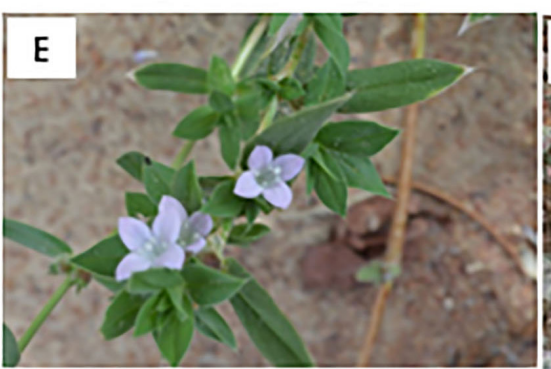

Diodellateres

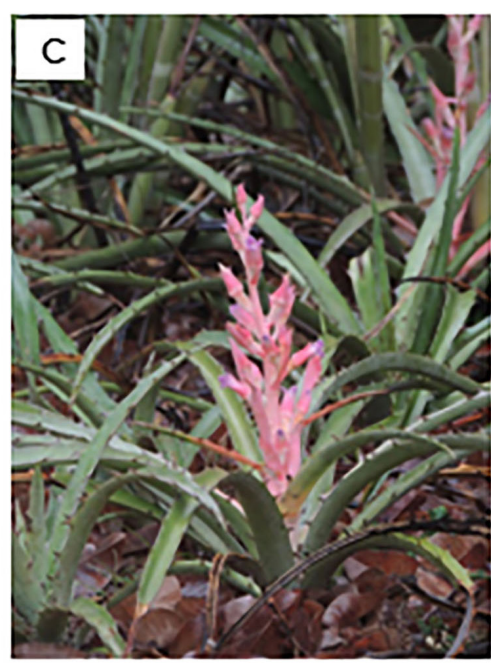

Bromelialaciniosa

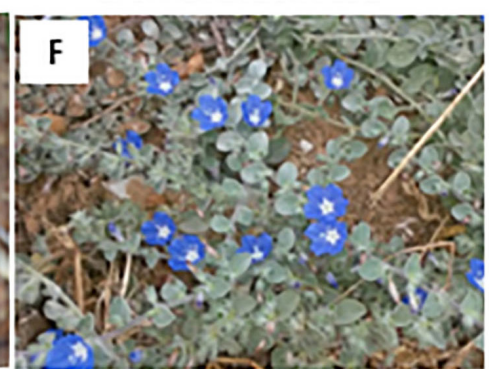

Evolvulus cordatus

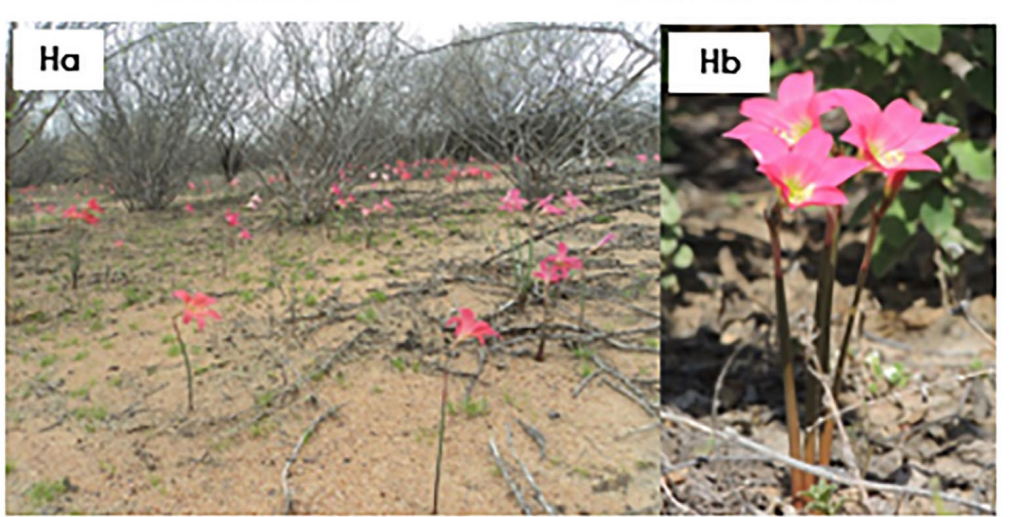

Habranthus sylvaticus

Gomphrena desertorum

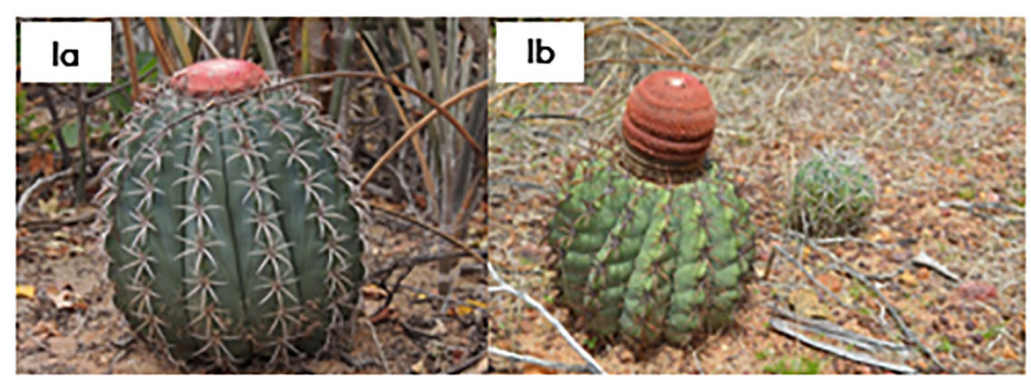

Melocactus zehntneri

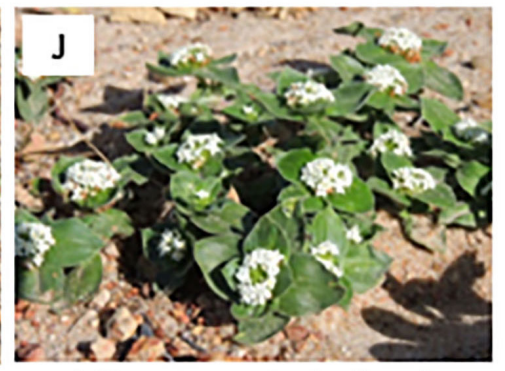

Mitracarpus baturitensis

Figura 3. Espécies de hábito herbáceo do Bioma Caatinga indicativas de uso no paisagismo. Características ornamentais do hábito, caule, flores/inflorescências, folhas e frutos (S). Petrolina-PE, 2014-2015. Fotos: Silva, H.L. da Costa \& Cotting, J.C. 


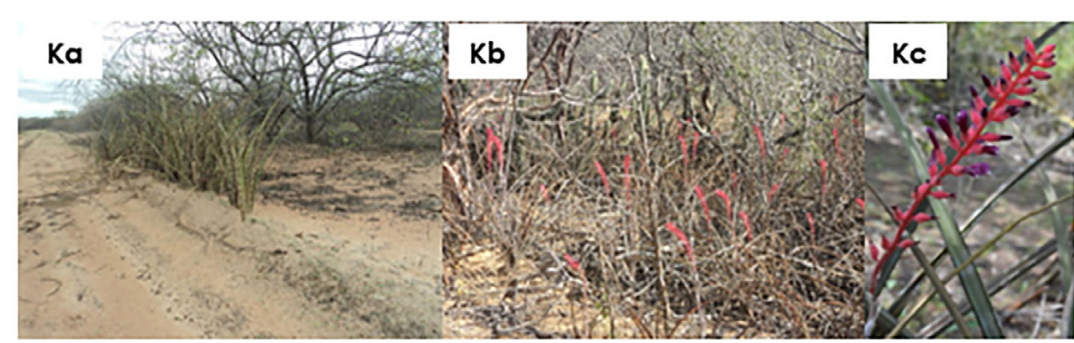

Neoglaziovia variegata
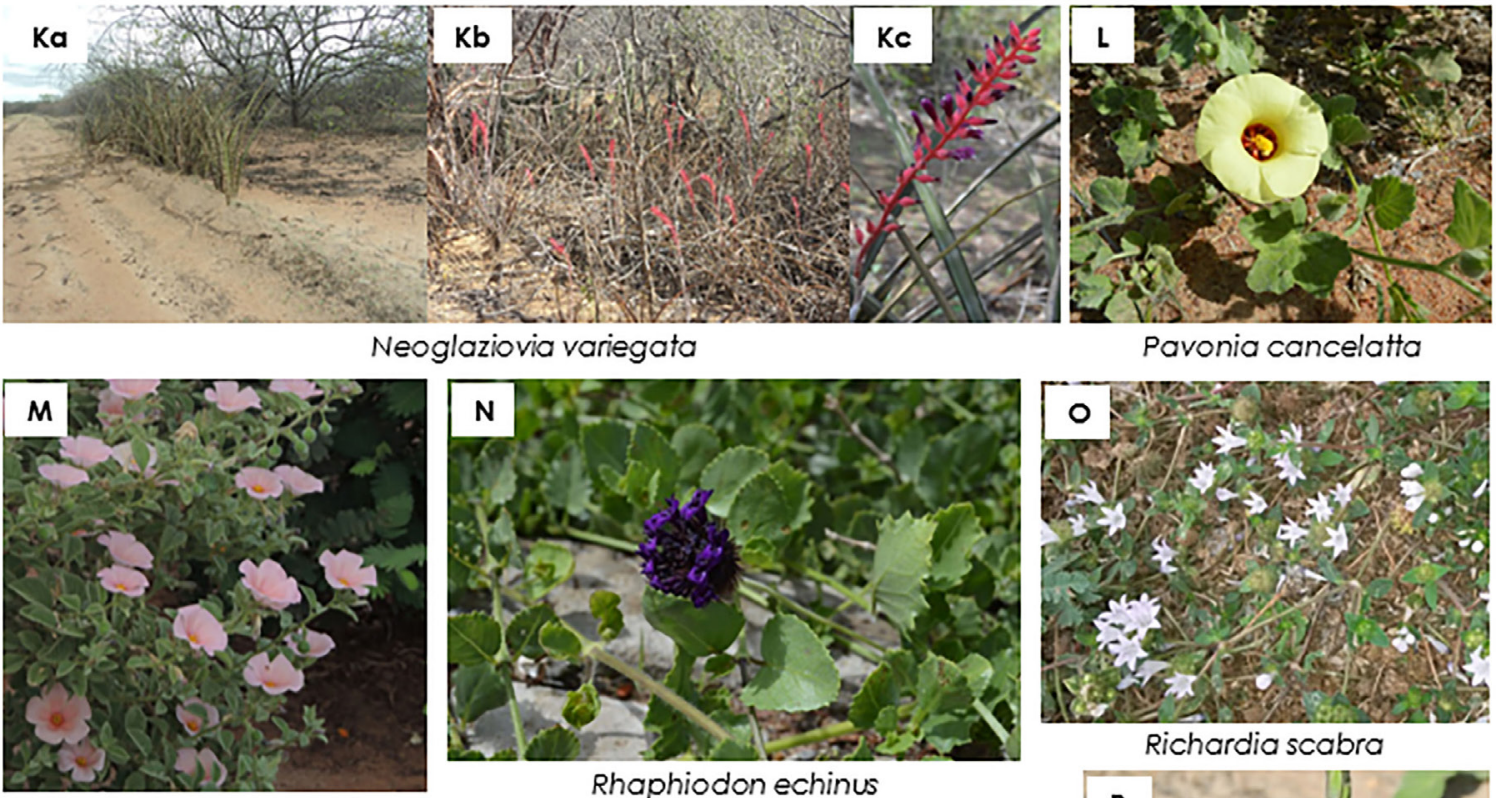

Pavonia cancelatta

Piriqueta duarteana

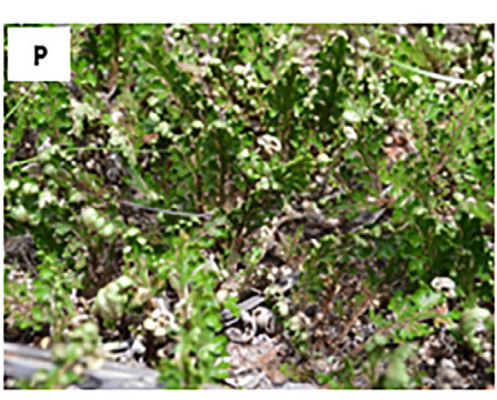

Rhaphiodon echinus

Selaginella convoluta

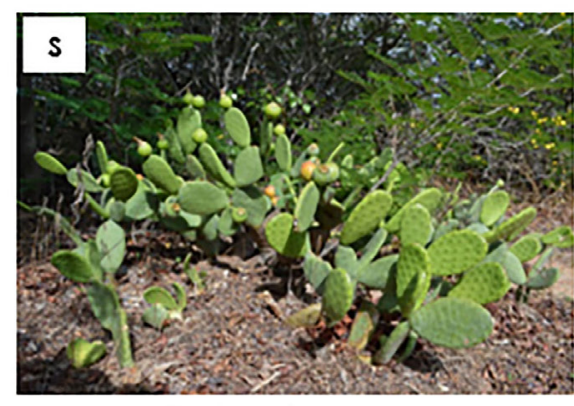

Tacinga inamoena

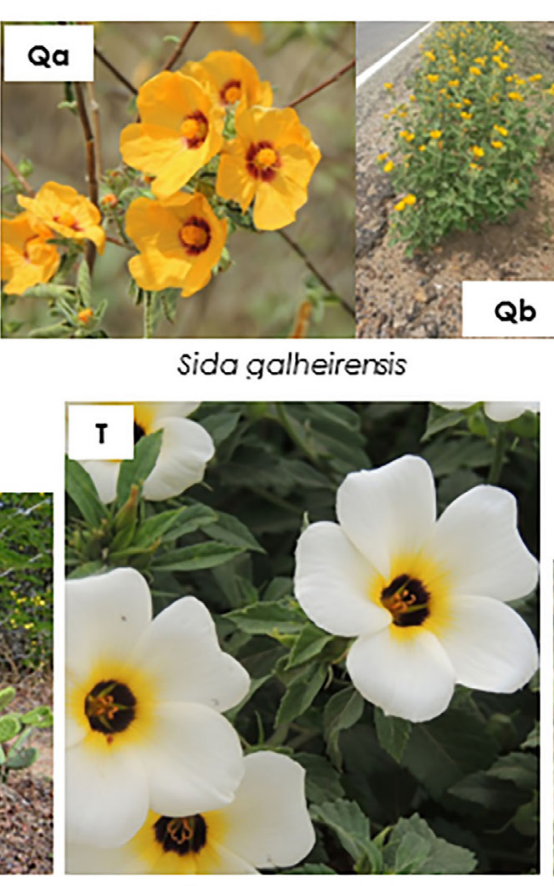

Turnera subulata

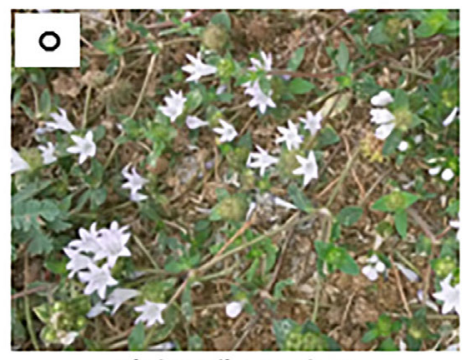

Richardia scabra

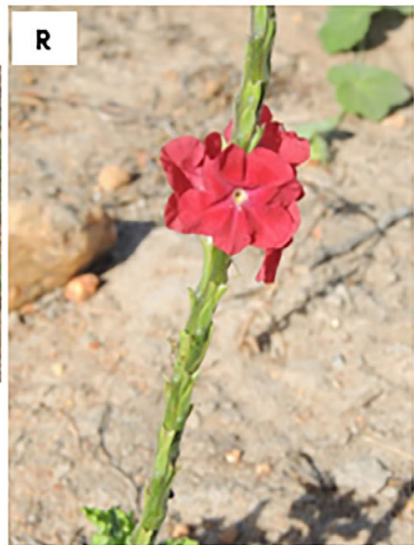

Stachytarpheta microphylla

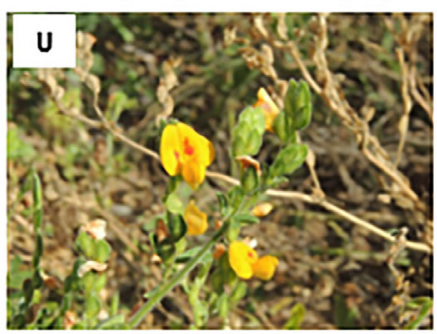

Zornia brasiliensis

Figura 4. Espécies de hábito herbáceo do Bioma Caatinga indicativas de uso no paisagismo. Características ornamentais do hábito, caule, flores/inflorescências, folhas e frutos (S). Petrolina-PE, 2014-2015. Fotos: Silva, H.L. da Costa \& Cotting, J.C.

Algumas espécies selecionadas podem apresentar dupla função, ou seja, para a formação de maciços e também recomendadas para cultivo em vaso (Tabela 2), a exemplo da Alophia linearis (Figura 3A) e Angelonia campestres (Figura 3B). As flores dessas espécies são de coloração roxa, considerada uma cor fria no paisagismo promovendo a sensação de calma e alívio, sendo assim indicadas para ambientes menores, jardins com espaços restritos (Alvarez \& Kiill, 2014). Nesta categoria, ainda se enquadram as espécies Melocactus zehntneri (cactácea) (Figura 3I) e as bromeliáceas Bromelia lacioniosa (Figura 3C) e Neoglaziovia variegata (Figura 4Kb), que em conjunto podem formar grandes maciços.

Kiill et al. (2013) evidenciam que em ambiente natural, os cactos juntamente com bromélias compõem harmoniosos jardins. Por outro lado, em função de apresentarem espinhos, requerem certo critério na escolha do lugar onde serão cultivadas, sendo o mais 
indicado para locais de restrita circulação, assim como sugeriram Stumpf et al. (2009) ao elegerem espécies do Bioma Pampa com espinhos. Estas são espécies que podem simbolizar o ecossistema típico em que se encontram, contribuindo para composições rústicas ou típicas regionais e fortalecendo o valor da flora local, inclusive atrativo ao turismo.

Ainda de acordo com Kiill et al. (2013), a N. variegata apresenta um porte elegante, folhas estreitas e lineares (Figura 4Ka), com listras alternadas, tipo zebrado, o que the confere aspecto peculiar. Apresenta inflorescência racemosa (Figura $4 \mathrm{KC}$ ), com tonalidade do vermelho ao rosa, localizada na parte central da planta. Suas flores são tubulares, com pedúnculo róseo e pétalas roxas. Durante as incursões em campo, observou-se longevidade de suas inflorescências. Embora o objeto de estudo fora plantas para paisagismo, as características desta espécie, sugerem um indicativo de uso para a arte floral, tanto suas folhas quanto suas hastes florais.

Para a formação de maciços também podem ser indicadas as espécies Piriqueta duarteana (Figura 4M), Sida galheirensis (Figura 4Qa e 4Qb), Stachytarpheta microphylla (Figura 4R), Tacinga inamoena (Figura 4S), Turnera subulata (Figura 4T), e Habranthus sylvaticus (Figura 3H). Estas espécies destacam-se pelo colorido das flores e volume que formam ao serem observadas em campo, apropriados para composição de maciços homogêneos. Destaca-se que a $H$. sylvaticus é uma espécie que apresenta bulbo e floresce somente quando iniciam as chuvas, após um período longo de estiagem (em torno de 9-10 meses), surgindo do solo árido e sem vegetação, belas flores que formam um tapete natural (Figura $3 \mathrm{Ha}$ e $3 \mathrm{Hb}$ ). Cabe salientar, que ao fazer uso de plantas para compor maciços, considera-se a associação de plantas de mesma espécie ou de espécies variadas, no qual a característica básica é um volume cheio em que o espaço ocupado tende a ser proporcionalmente igual em horizontalidade e verticalidade, tendendo mais para o horizontal. Das espécies indicadas para maciço, S. galheirensis (Figura 4Qb) também pode ser utilizada para formar bordaduras, no qual prevalece a linearidade de um porte menor. Este tipo de efeito tende a compor as bordas de um canteiro ou de um caminho, por exemplo.

As espécies de hábito arbustivo (Figura 5) representam 25,6\% das plantas prospectadas para uso o paisagismo. Dentre estas, $54,5 \%$ são representantes da família Fabaceae (Tabela 2), destacando-se Calliandra leptopoda (Figura 5B), Calliandra macrocalyx, Mimosa ophthalmocentra. Mimosa verrucosa, Poincianella microphylla (Figura 5D) e Senna martiana (Figura 5F). Estas espécies podem ser cultivadas isoladamente por apresentarem volume suficiente destacando-se na paisagem e podem se sobressair às árvores pela plasticidade quanto às formas, cores e volumes diferenciados. As caliandras e mimosas, por exemplo, aparentam ter arquitetura moldável para bonsais, pois apresentam muitas ramificações, tamanho pequeno das folhas e parece resistir a podas drásticas, aramações e intervenções em suas raízes, além da beleza de sua floração. A P. microphylla apresenta plasticidade para topiarias (arte de moldar plantas)sugerindo-se iniciar quando a planta ainda é jovem para uma boa formação.

A espécie S. martiana (Figura 5F), embora tenha volume suficiente para ser cultivada de forma isolada, recomenda-se também o cultivo em maciço, pelo efeito contrastante que formam quando encontradas próximas uma da outra, compondo assim maciços homogêneos. Biondi (2013) recomenda também seu uso em canteiros centrais para diminuir o ofuscamento. Também as espécies Ruellia asperula (Figura 5E) e Varronia leococephala (Figura 5G), cujas inflorescências são as principais características ornamentais, podem ser cultivadas isoladamente, no entanto, sugere-se que estas sejam cultivadas em maciços, para que se destaquem na paisagem e possam gerar os benefícios estéticos e funcionais. $O$ encanto destas plantas reside na sua floração. A R. aspérula (Figura 5Eb), por apresentar flores tubulosas é polinizada por beijaflores, característica interessante por atrair aves.

As arbustivas Allamanda puberula (Figura 5A) e Jatropha mollissima (Figura 5C), além do cultivo isolado, podem ser indicadas 
para formação de cercas-vivas (Tabela 2). Apresentam formato verticalizado mais aberto, promovendo uma assimetria. De acordo com Malamut (2014), o afloramento dos caules junto ao solo permite a formação de conjuntos vegetacionais onde as plantas perdem a sua individualidade e passam a formar associações, característica útil para cerca-vivas, e, um cultivo mais adensado destas espécies, pode resultar numa cerca-viva mais fechada. A espécie Vellozia cinerascens (Figura $5 \mathrm{H}$ ) apresenta uso multifuncional seja isolada em jardins ou em
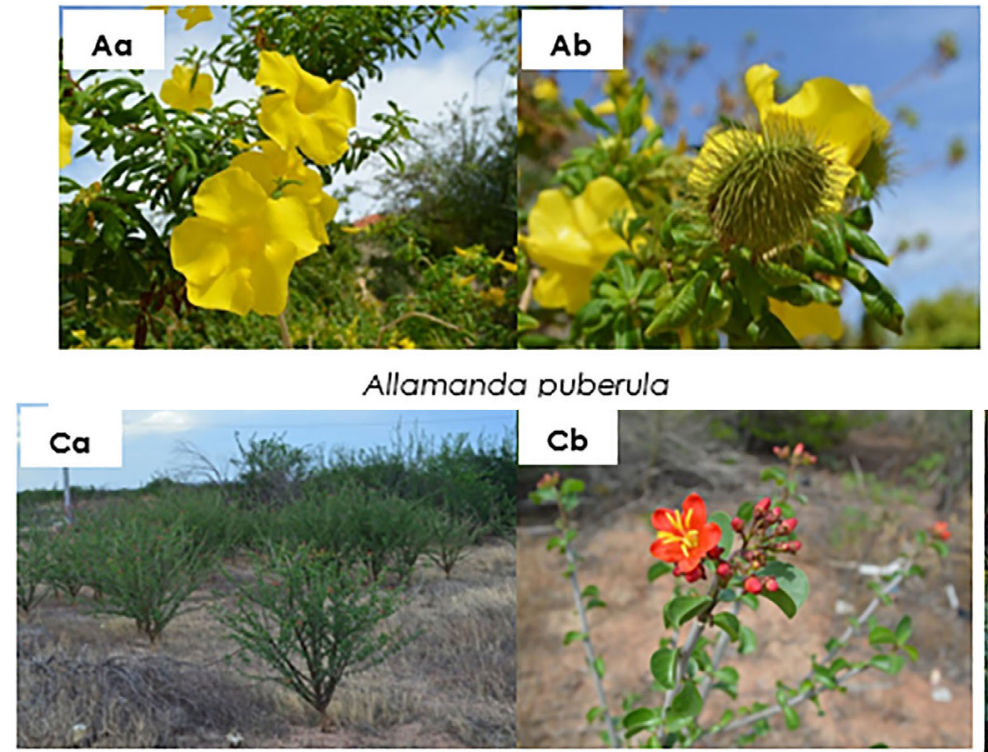

Jatropha mollissima

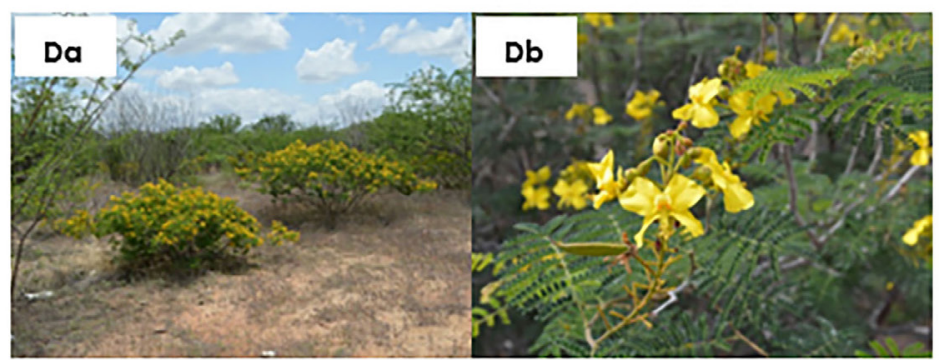

Poincianella microphylla

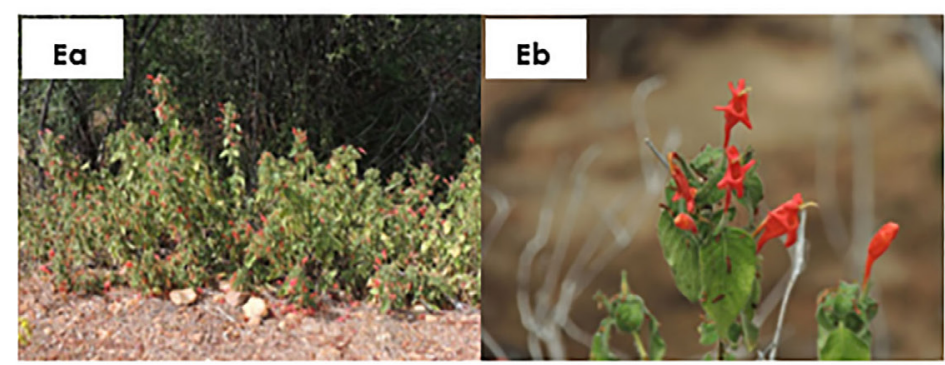

Ruellia asperula

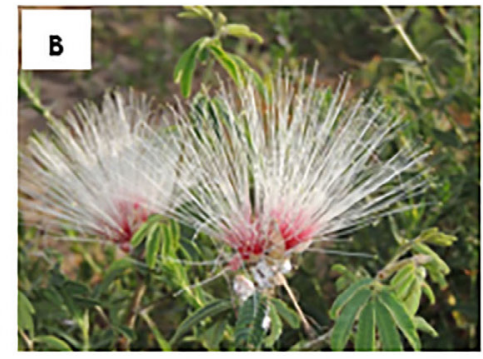

Calliandra macrocalyx

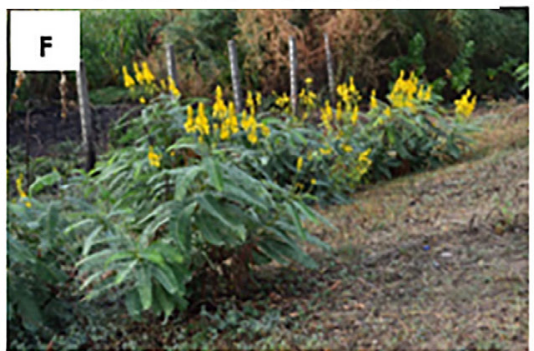

Senna martiana

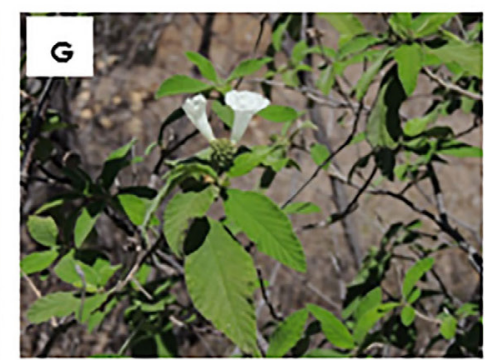

Varronia leucocephala

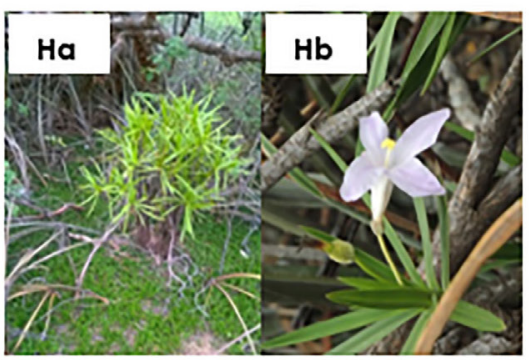

Vellozia cinerascens

Figura 5. Espécies arbustivas do Bioma Caatinga indicativas de uso no paisagismo. Características ornamentais do hábito (Ca, Da, Ea, F, Ha); Flores/Inflorescências (Aa, B, Cb, Db, F, G, Eb, Hb); Folhas (Cb, Db, Ha); Frutos (Ab). Petrolina-PE, 2014-2015. Fotos: Silva, H.L. da Costa \& Cotting, J.C.

vaso (Tabela 2). Torna-se ornamental pelas flores (Figura 5Ha) que apresenta, no entanto, encanta pelo seu conjunto, coloração e beleza da folhagem (Figura $5 \mathrm{Hb}$ ).

Com relação às espécies arbóreas
(Figura 2), sugere-se a indicação de nove espécies (Tabela 2), e em sua totalidade podem ser indicadas para cultivo isolado, no entanto, não impede que sejam cultivadas formando grandes maciços ou ainda, formando maciços 
heterogêneos. Malamut (2014) descreve a importância do uso de árvores para compor cenários de paisagismo, por serem úteis para sombrear pisos e fachadas, melhorando a qualidade térmica do ambiente as quais serão inseridas. Anadenanthera colubrina (Figura 2B), por exemplo, se destaca na paisagem pelo brilho de suas folhas verde-amareladas, enquanto a Amburana cearencis (Figura 2A), Fraunhofera multiflora (Figura 2F), Libidibia ferrea (Figura 2G), Luetzelburgia bahiensis (Figura 2H) e S. brasiliensis (Figura 2l), destacam-se também pelas flores, que além da beleza, em sua maioria apresentam aroma agradável. A espécie Commiphora leptophloeos é decídua (Figura 2Ea), no entanto suas folhas são aromáticas e destaca-se no ambiente por seu tronco contorcido e avermelhado (Figura 2Eb). Dentre as arbóreas, encontra-se a cactácea Cereus jamacaru (Figura 2C), árvore áfila, imponente, que apresenta floração exuberante embora efêmera e, simboliza uma espécie típica do Bioma Caatinga.

O uso de espécies arbóreas nativas, da flora regional à exóticas deve prevalecer, no entanto, como sugere Alvarez et al. (2012), de forma sustentável para não causar risco de extinção, não só arbóreas, mas também de organismos que dela dependem. Ainda segundo estes autores, poucas são as cidades no Semiárido que utilizam em seu paisagismo espécies arbóreas da Caatinga. Estudos realizados por Calixto Junior et al. (2009) e Lima Neto \& Melo e Souza (2011), e, evidenciaram a dominância de espécies exóticas na arborização urbana em cidades do nordeste brasileiro. Fazer uso de espécies arbóreas nativas com indicação para paisagismo é fundamental, pois são adaptadas às condições de clima e solo, podem apresentar maior resistência a pragas e doenças e contribuem para conservação do patrimônio genético e da biodiversidade. Alvarez et al. (2012), também recomendam as espécies A. cearensis, P. simplicifolium, S. brasiliensis e Commiphora leptophloeos para serem utilizadas na arborização urbana.

A espécie arbórea C. quercifolius (Figura 2D) se desta no ambiente natural por apresentar uma estrutura verticalizada mais aberta, ramificando desde a base, no entanto, é totalmente espinescente. Com apelo no paisagismo, pode ser introduzida em cultivo isolado, mas deduz-se que se cultivada de forma adensada poderia ser utilizada como cerca-viva para formar uma barreira física, de proteção.

A espécie Ipomea incarnata (Figura 6A), uma trepadeira herbácea, se desenvolve muito bem em épocas de chuva na Caatinga, tem a capacidade de escalar cercas de propriedades rurais (Figura 6Aa) e arbustos (Figura 6Ab) decorando, naturalmente, esses suportes, como mencionam Castro \& Cavalcante (2010). A Dioclea grandiflora (Figura 6B), um cipó vigoroso, exclusivo da Caatinga brasileira, apresenta inflorescências elegantes e atraentes nas extremidades dos ramos com flores roxas (Figura 6Ba e 6Bb). Ambas as espécies podem ser cultivadas isoladamente, e em função do seu hábito de crescimento, acabam proporcionando a ideia de serem vários os indivíduos que causam o efeito paisagístico de revestimento. Estes tipos de plantas, segundo Malamut (2014), podem ser utilizadas para encobrimento de muros ou estruturas indesejáveis, para cobrir pérgolas, proporcionando espaços sombreados ou para criar painéis verticais, ornamentando fachadas ou criando barreiras visuais para áreas privativas.

Castro \& Cavalcante (2010), na busca por plantas nativas do Bioma Caatinga que pudessem ser aproveitadas, por meio de estudos, exploração e comercialização adequados, indicam uma serie de espécies com potencialidades ornamentais. Dentre as herbáceas elencadas também sugeriram as espécies S. galheirensis, T. inamoena e H. sylvaticus), para arbustos (J. mollissima, R. asperula, V. leococephala e espécies do gênero Calliandra e Mimosa), para arbóreas (A. cearencis, A. colubrina, C. jamacaru e espécies do gênero Senna e Poincianella), trepadeiras (espécies do gênero Ipomoea) e como cipó também indicaram D. grandiflora.

De acordo com Souza et al. (2012), as espécies nativas do Bioma Caatinga, de diferentes hábitos de vida são úteis nos jardins diversificados e heterogêneos, formando ambientes com características singulares, 
com vistas à substituição de modo eficiente e sustentável aquelas tradicionalmente empregadas em projetos de paisagismo.

De acordo com Leal \& Biondi (2006) a análise de variáveis estéticas é importante para indicar a melhor utilização das espécies em um projeto paisagístico. Percebe-se que os ecossistemas rurais e urbanos do semiárido nordestino, inserido numa região de clima quente e seco, com período de até nove

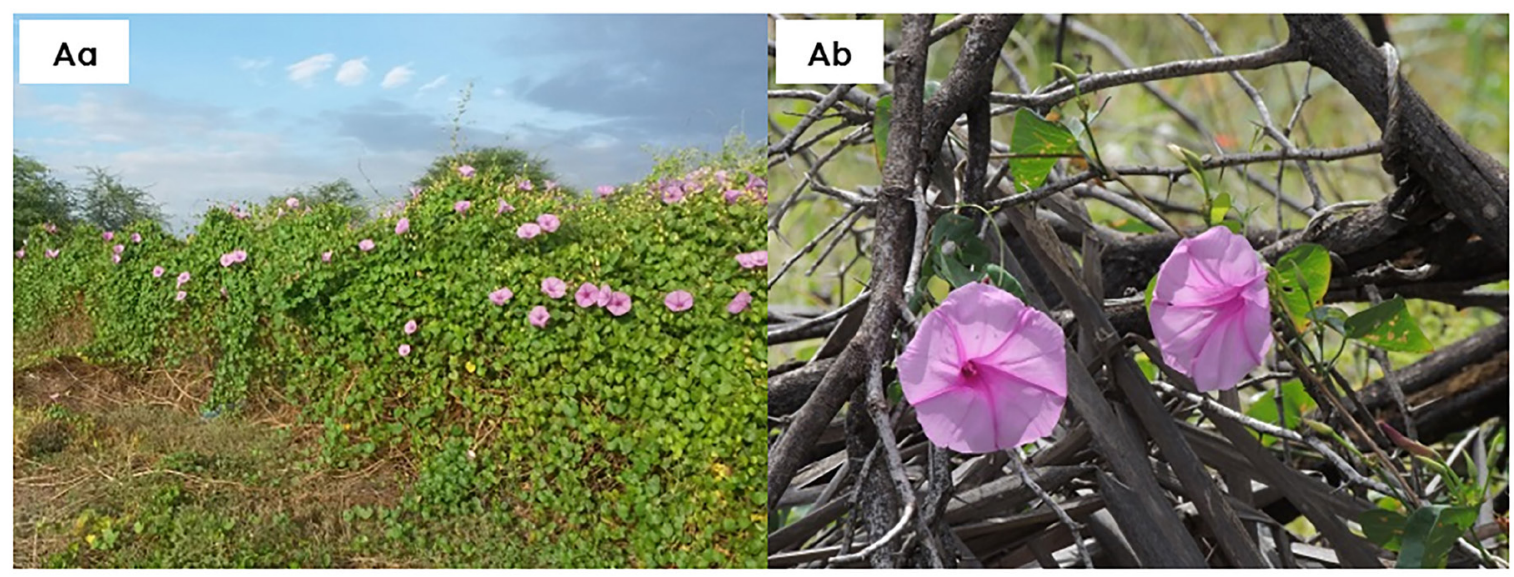

Ipomoea incarnata

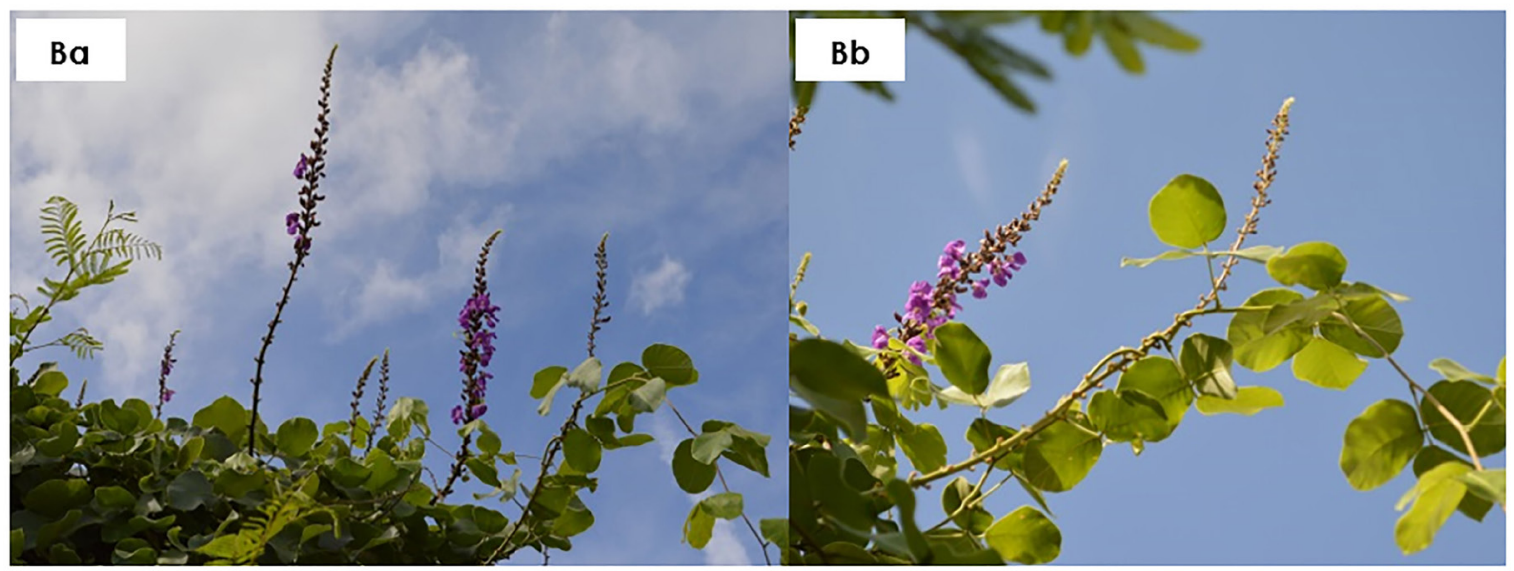

Dioclea grandiflora

Figura 6. Espécie trepadeira e cipó do Bioma Caatinga indicativas de uso no paisagismo. Características ornamentais do hábito (Aa, Ba); Flores/Inflorescências (Ab, Bb). Petrolina-PE, 2014-2015. Fotos: Silva, H.L. da Costa \& Cotting, J.C.

meses de estiagem, necessitam da presença de vegetação que proporcione melhorias estéticas e funcionais em suas paisagens. Considerando que as espécies indicadas estão adaptadas a estas condições, ao serem introduzidas, podem apresentar melhor desenvolvimento, menor custo de manutenção com relação às espécies exóticas além da conservação ex situ.

As espécies prospectadas podem ser aproveitadas em suas diferentes formas tornandose sinônimo de fonte de renda para população local bem como, poderão tornar-se numa forma de divulgação e valorização da flora local. No entanto, vale ressaltar que há necessidade de estudos mais aprimorados, sugerindo-se estabelecer protocolos de propagação e auxílio do melhoramento genético, sem, contudo levalas à extinção.

\section{Conclusões}

É possivel afirmar que o Vale do Submédio São Francisco, inserido no Bioma Caatinga, abriga inúmeras espécies nativas cujas características mostram adequação ornamental para uso no paisagismo.

Todas as espécies analisadas apresentam um grande potencial para diversos usos e efeitos paisagísticos.

A indicação do potencial ornamental das 43 espécies analisadas reforça e estimula 
o uso de espécies nativas do Bioma Caatinga em projetos de paisagismo, cujo potencial ornamental ainda é pouco valorizado.

\section{Agradecimentos}

Ao apoio financeiro do CNPa pela bolsa de iniciação científica do segundo autor e à equipe do HVASF, em nome do último autor, por disponibilizar o Software Carolus.

\section{Referências}

Alvarez, I.A., Kiill, L.H.P. 2014. Arborização, floricultura e paisagismo com plantas da Caatinga. Informativo Abrates 24: 63-67.

Alvarez, I.A., Oliveira, U.R., Mattos, P.P. de, Braz, E.M., Canetti, A. 2012. Arborização urbana no semiárido: espécies potenciais da Caatinga. Embrapa Florestas, Colombo, Brasil. 28p. (Documentos, 243).

Beckmann-Cavalcante, M.Z., Amaral, G.C., Avelino, R.C., Brito, L.P. da S., Cavalcante, I.H.L. (2014). Propagação de Alternanthera dentata pelo processo de estaquia. Comunicata Scientiae 5: 170-177.

Biondi, D. 2013. Paisagismo rodoviário: indicação de espécies. O Autor, Curitiba, Brasil. $54 \mathrm{p}$.

Calixto Junior, J.T., Santana, G.M., Lira Filho, J.A. 2009. Análise quantitativa da arborização urbana de Lavra da Mangabeira, CE, Nordeste do Brasil. Revista da Sociedade Brasileira de Arborização Urbana 4: 99-109.

Cardoso, J.C. 2013. Melhoramento de espécies ornamentais como estratégia para o desenvolvimento e autossuficiência do setor. Horticultura Brasileira 31: 1-1.

Castro, A.S., Cavalcante, A. 2010. Flores da Caatinga. INSA, Campina Grande, Brasil. 114 p.

Fischer, S.Z., Stumpf, E.R.T., Heiden, G., Barbieri, R.L., Wasum, R.A. 2007. Plantas da flora brasileira no mercado internacional de floricultura. Revista Brasileira de Biociências: 510512.

Forzza, R.C., Baumgratz, J.F.A., Bicudo, C.E.M., Canhos, D.A.L., Carvalho Jr., A.A., Coelho, M.A.N., Costa, A.F., Costa, D.P., Hopkins, M.G., Leitman, P.M., Lohmann, L.G., Lughadha, E.N., Maia, L.C., Martinelli, G., Menezes, M.,
Morim, M.P., Peixoto, A.L., Pirani, J.R., Prado, J., Queiroz, L.P., Souza, S., Souza, V.C., Stehmann, J.R., Sylvestre, L.S., Walter, B.M., Zappi, D.C. 2012. New Brazilian floristic list highlights conservation challenges. BioScience 62: 39-45.

Heiden, G., Barbieri, R.L., Stumpf, E.T. 2006. Considerações sobre o uso de plantas ornamentais nativas. Revista Brasileira de Horticultura Ornamental 12: 1-7.

Heiden, G., Stumpf, E.R.T., Barbieri, R.L., Grolli, P.R. 2007a. Uso de plantas subarbustivas e herbáceas nativas do Rio Grande do Sul como alternativa a ornamentais exóticas. Revista Brasileira de Agroecologia: 850-853.

Heiden, G., Stumpf, E.R.T., Barbieri, R.L., Grolli, P.R. 2007b. Uso de plantas arbóreas e arbustivas nativas do Rio Grande do Sul como alternativa a ornamentais exóticas. Revista Brasileira de Agroecologia: 854-857.

IBGE. Instituto Brasileiro de Geografia e Estatística. 2012. Manual técnico da vegetação do Brasil. 2. ed. IBGE, Rio de Janeiro, Brasil. 274 p.

Kiill, L.H.P., Terao, D., Alvarez, I.A. 2013. Plantas ornamentais da Caatinga. Embrapa, Brasília, Brasil. $139 \mathrm{p}$.

Leal, I., Biondi, D. 2006. Potencial ornamental de espécies nativas. Revista Científica Eletrônica de Engenharia Florestal 8: $1-16$.

Lima Neto, E.M., Melo e Souza, R. 2011. Comportamento e características das espécies arbóreas nas áreas verdes públicas de Aracaju, Sergipe. Scientia Plena 7: 1-10.

Loiola, M.I.B., Roque, A. de A., Oliveira, AC.P. de. 2012. Caatinga: Vegetação do semiárido brasileiro. Ecologia 4: 14-19.

Malamut, M. 2014. Paisagismo: projetando espaços livres. Livro.com, Lauro de Freitas, Brasil. $148 \mathrm{p}$.

Reflora. Flora do Brasil 2020 em construção. Jardim Botânico do Rio de Janeiro. 2016. http://floradobrasil.jbrj.gov.br/ <Acesso em 15 Jun. 2016>

Sales-Rodrigues, J., Brasileiro, J.C.B., Melo, J.I.M. de. 2014. Flora de um inselberg na mesorregião agreste do Estado da ParaíbaBrasil. Polibotánica 37: 47-61.

Siqueira Filho, J.A. 2012. A flora das Caatingas do Rio São Francisco: história natural 
e conservação. Editora Andrea Jakobsson, Rio de Janeiro, Brasil. 552 p.

Souza, C.O. de, Vieira, D.C.M., Socolowski, F., Siqueira Filho, J.A. A Caatinga possui espécies de plantas ornamentais para uso paisagístico? 2012. http://www.botanica. org.br/trabalhos-cientificos/63CNBot/63CNBot_ stax_233.pdf <Acesso em 17 de Jan. 2017>

Stumpf, E.R.T., Barbieri, R.L., Heiden, G., Fischer, S.Z., Neitzke, R.S. 2008. Potencialidade ornamental de espécies de Eryngium (Apiaceae) ocorrentes nos campos do Rio Grande do Sul. Magistra 20: 256-263.

Stumpf, E.R.T., Romano, C.M., Barbieri, R.L., Heiden, G., Fischer, S.Z., Corrêa, L.B. 2009. Características ornamentais de plantas do Bioma Pampa. Revista Brasileira de Horticultura Ornamental 15: 49-62. 